\title{
Risk Assessment Research of college students online entrepreneurship based on Disturbing Fuzzy Comprehensive Evaluation
}

\author{
Binye $\mathrm{Wu}^{1, \mathrm{a}}$,Xuejiao $\mathrm{Wu}^{2, \mathrm{~b}}$, Xiaolong $\mathrm{Ma}^{3, \mathrm{c}}$,Xufeng $\mathrm{Tao}^{4, \mathrm{~d}}$ and Jiawei Fang ${ }^{5, \mathrm{e}}$ \\ 128 Dormitory East Campus in Quuzhen School of HuzhouTeachers College , \\ HuzhouCity,ZhejiangProvince,China \\ ${ }^{2}$ Class 1 of Grade 10,Foreign Language Department of City College Wenzhou University, \\ Wenzhou City, Zhejiang Province, China \\ ${ }^{3}$ HuzhouTeachers College ,Huzhou City, Zhejiang Province, China \\ 416DormitoryMiddleCampus inHuzhouTeachers College ,Huzhou City, Zhejiang Province, China \\ ${ }^{5}$ 25Dormitory East Campus in Qiuzhen School of HuzhouTeachers College , Huzhou City, Zhejiang \\ Province, China \\ a18767226928@163.com,bwuccwuxuejiao163.com,clxm2007@sohu.com dtaoxf9109@hotmail.com, \\ ehzxsjsxxw@gmail.com
}

Keywords: disturbing fuzzy comprehensive evaluation method; college students online entrepreneurship; risk assessment

\begin{abstract}
The current situation of college graduates employment is severe and complex, college students entrepreneurship has attracted more and more attention, andonline entrepreneurship has been a fashion but existing risks. This paper presents apattern and method of disturbing fuzzy comprehensive evaluation method of collegestudents' online entrepreneurship risk. For entrepreneu rial risk are analyzed and the optimal discriminant, and finding the main factors that lead to risk so as to provide a scientific basis for college students online entrepreneurship risk management.
\end{abstract}

\section{Review of Research}

According to search CNKI, WANFANG, Weipu and some others domestic representative journals, conference, dissertation database, we found the research on college students online entrepreneurship mainly focuses on following aspects.

(1) The research on the pattern of college students' online entrepreneurship which is on the basis of e-commerce. This field mainly studies the basic pattern of college students' online entrepreneurship. For example, the passage named deep analysis of the pattern of college students online entrepreneurship wrote by SuiFei in Henan University of Technology points out that the main patterns of college student's online entrepreneurship are the network technology shares pattern, website promotion pattern, e-commerce pattern, network advertising pattern, data service agent pattern, content charging pattern. These pattern are suitable for college students' online entrepreneurship, but there exists in reality, such as lacking of technological support and venture capital.

(2) The feasibility analysis and countermeasure research of college students' online entrepreneurship.This filed mainly researches on the popularity of the Internet, rapid development of e-commerce and advantages of online entrepreneurship (low entrance, low risks and convenient promotion), which made online entrepreneurship a new choice for college graduates employment. For example, the paper the feasibility analysis and countermeasure research of college students' 
online entrepreneurship issued by Yang Haijuan, it mainly researches on the feasibility analysis and countermeasure research of college students' online entrepreneurship. And also the paper Study on the key success factors and countermeasures of college students' online entrepreneurship issued by Zhang Xiangyang, according to the research and analysis, finding that college entrepreneur lack of social experience, the market environment is not perfect and the government must strengthen the construction of entrepreneurial environment.

(3) Research on the risk of college students' online entrepreneurship. This field's research is also mainly remaining in the qualitative research level. For example, the paper Risk analysis and countermeasure research of college students' online entrepreneurship issued by Cheng Heping. The article tries to combine the characteristics of the college students themselves so as to raise corresponding counterplan due to the risk analysis which appears in online entrepreneurship.

However, the study which combines quantitative and qualitative analysis of college students' online entrepreneurship is less. This paper researches on this, via analyzing factors which impact college students' online entrepreneurship, and disturbance fuzzy comprehensive evaluation method was used to study with the method of quantitative and qualitative combined, by studying of changes in the various factors to provide reference for the college students' online entrepreneurship risk, to manage risk effectively risk, to improve the rate of entrepreneurial success, to realize the value of life and better to create value for society at the same time.

\section{The construction of risk index of college students' online entrepreneurship}

College students are a special group; they dare to challenge and adventure, and have strong independence. Meanwhile, they have strong ability to learn and apply network technology. But through the relevant investigation and a lot of periodical literature by author, it was found that there exists a high risk for college students' online entrepreneurship and lower rate of success. So author concludes the risk factors which impact college students' online entrepreneurship.

\subsection{Risks of social environment}

The main risks of social environment of college students' online entrepreneurship can be divided into several types. They are risks of market competition, policy of government entrepreneurship, risks of network information and risks of laws and regulations. At present there are many suitable models for college students' online entrepreneurship, the most common way is to open an online store based on the third party of network platform, such as to open a store on Taobao. However, in the operation of online store, college students are not sensitive enough to analyze market, they lack of necessary analysis-oriented for market demand, as a result they in the inferior position in the same industry. At present, in our country the Internet intellectual property rights, e-commerce tax revenue, e-contract, e-evidence and other laws and regulations are not sound, therefore network environment is not very stable, it must strengthen caution during the transaction.

\subsection{Management risk}

The major management risks of college students' online entrepreneurship are management risks of customer relations, leader's qualities and abilities, management risks of operation, the contradiction between entrepreneurship and study, management risks of human resources and finance.

To set up and maintain good customer relations is the basis of the successful operation of enterprises. As college students' entrepreneurship groups lack social experience and social cognition. Although they have passion for entrepreneurship, they are not good at setting up and maintaining good customer relations, they cannot understand consumer's needs correctly,at the 
same time they lack management risks of enterprise's operation. Meanwhile, they should complete the prescribed corresponding course and other activities during the period of university, with the limited time and energy, how to deal with the contradiction between study and entrepreneurship is a problem for entrepreneur must consider.

Along with the development of enterprise's operation, and the business tends more complicated, team management requires professionalization, so the leader's ability is a major factor. The college students are consumer groups, they haven't got jobs yet, generally speaking they are supported by family. Therefore, if college students want to carve out their business, the initial money for entrepreneurship is a vital problem. The proportion of input and output of entrepreneurship also exists unbalance, high input and low output has been a very common phenomenon for college students' entrepreneurship, which made funds not flow.

\subsection{Project selection risk}

Risks of project selection for college student's online entrepreneurship are including the formation of entrepreneurship team, the selection of e-commerce entrepreneurial model, the ability to raise entrepreneurial capital, the risk of project itself and the risk of entrepreneurial industry.

As the network technology continues to mature, the model of college student's online entrepreneurship gets innovation gradually, it breaks store model with the help of the third party network platform, such as building website autonomously. Consequently, different project selection as well as team's formation impact on enterprise's operation. Alternative and complementarities of goods and other industry internal risks would affect the operation of the project itself.

\subsection{Technology risk}

The technology risk of college students' online entrepreneurship is mainly Operations management technology, data mining and integration of the difficulty, website design and production and application of information technology. After college students' entrepreneurship team finds a proper project, it should be considered whether it is necessary to build a website, the stand or fall of website construction affect the site operations. The more the website traffic and data has the more detailed, it has significant meaning for switching orders. The specialized knowledge of college students is not solid, and they are not knowledgeable with low weak ability to apply information technology.

\subsection{Risks of college entrepreneurship support}

The risks of college entrepreneurship support includes the training of Network entrepreneurial skills, holding network entrepreneurship competition, education of venture investment and education of career planning. Generally, colleges provides career planning education for students, however it is uncommon to educate in venture investment. With the rapid of development of Internet, many college students are strong-willed to start their business online, but it requires high specialization and needs schools' entrepreneurship training.

\section{Improvement of Fuzzy Comprehensive Assessment}

Fuzzy comprehensive evaluation theory is presented by the United States-control expert at the University of California at Berkeley Chad (L.A.Zadeh) Professor, based on the theory of fuzzy membership degree to a quantitative evaluation qualitative evaluation, its result is clear, with strong performance, but still there are certain shortcomings in the practical application. Therefore some scholars improve the fuzzy comprehensive evaluation method --disturbing fuzzy comprehensive evaluation methods. 


\section{Implementation of disturbance fuzzy comprehensive evaluation method of college students' online entrepreneurship}

\subsection{Evaluation factors set of construction of college student's online entrepreneurship risk}

The evaluation factors refer to the collection of which evaluation objects involved in the various influencing factors. According to the above analysis of factors influencing college students online entrepreneurship risk, establishing factors of college students' starting online business risk assessment set.

Tthefirst level risk factor setare: $U=\left(\right.$ Risks of social environment $U_{1}$,Management risk; $U_{2}$;Project selection risk $U_{3}$; Technical risk $U_{4}$; Risks of college entrepreneurial support $U_{5}$ ).

The second level factor set are: Risks of social environment $\mathrm{U}_{1}=$ (Market competition risk $\mathrm{U}_{11}$, Government entrepreneurship policy $\mathrm{U}_{12}$, Network information risk $\mathrm{U}_{13}$, Laws and regulations risk $\mathrm{U}_{14}$ ), Management risk; $\mathrm{U}_{2}=$ (customer relationship management risk $\mathrm{U}_{21}$,Leaders' qualities and capability $\mathrm{U}_{22}$ Operation management risk $\mathrm{U}_{23}$, The contradiction between business and study $\mathrm{U}_{24}$,Human resource management risk $\mathrm{U}_{25}$,Financial management risk $\mathrm{U}_{26}$ ); Project selection risk $\mathrm{U}_{3}=\left(\right.$ The formation of entrepreneurial team $\mathrm{U}_{31}$, The choice of e-commerce business models $\mathrm{U}_{32}$,Venture financing capacity $\mathrm{U}_{33}$, The risk of the project itself $\mathrm{U}_{34}$, Choice of venture industries $\mathrm{U}_{35}$ ); Technical risk $\mathrm{U}_{4}=\left(\right.$ Operations Management Technology $\mathrm{U}_{41}$, Data mining and integration difficulty $\mathrm{U}_{42}$, Website design and production $\mathrm{U}_{43}$,Application of information technology risk $\mathrm{U}_{44}$ ); Risks of college entrepreneurial support $\mathrm{U}_{5}=\left(\right.$ Network of entrepreneurial skills training $\mathrm{U}_{51}$, On network entrepreneurship competition $\mathrm{U}_{52}$, Venture capital education $\mathrm{U}_{53}$, Career planning education $\mathrm{U}_{54}$ ).

\subsection{Confirmation ofevaluation set of college students' online entrepreneurship risk}

The evaluation set is a kind of language description of each level evaluation indexes, and it is the collection which reviewers give comments on various indicators. Comments in this article are divided into five levels. Specific evaluation grade is: $v=\left(v_{1}, v_{2}, v_{3}, v_{4}, v_{5}\right)=\{$ higher, high, medium, low, lower\}.

\subsection{To determine the weighting set ofcollege students online entrepreneurship risk factors}

To determine the weights of all the risk factors is the key link of college students' online entrepreneurship risk identification; different weighting factors reflect different importance of factors. To scientifically determine the weight of the indicators, through the questionnaires, sent to experienced experts and teachers, author has gave importance assessment of the factors affecting college students'college students online entrepreneurship and to integrate the results, getting membership intervals, asfollows. Let the first layer indicator's weights set be $A=\left(\left[\begin{array}{ll}a_{1}, & \left.a_{1}{ }^{\prime}\right]\end{array}\right],\left[a_{2}\right.\right.$,

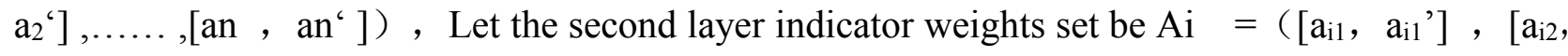
$\left.\mathrm{a}_{\mathrm{i} 2}{ }^{\prime}\right], \ldots . .,\left[\mathrm{a}_{\mathrm{im}}, \mathrm{a}_{\mathrm{im}}{ }^{\prime}\right]$ ).

$$
\begin{aligned}
& \mathrm{A}=\{[0.18,0.24],[0.30,0.36],[0.22,0.28],[0.11,0.18],[0.05,0.12]\} \\
& \mathrm{A}_{1}=\{[0.35,0.45],[0.10,0.15],[0.25,0.35],[0.05,0.12]\} \\
& \mathrm{A}_{2}=\{[0.20,0.30],[0.38,0.48],[0.25,0.30],[0.12,0.20],[0.15,0.22],[0.18,0.25]\} \\
& \mathrm{A}_{3}=\{[0.25,0.30],[0.05,0.12],[0.35,0.45],[0.18,0.25],[0.08,0.15]\} \\
& \mathrm{A}_{4}=\{[0.15,0.20],[0.25,0.30],[0.30,0.35],[0.10,0.15]\} \\
& \mathrm{A}_{5}=\{[0.22,0.28],[0.20,0.25],[0.28,0.34],[0.08,0.18]\}
\end{aligned}
$$

4.4 To determine the grade of membership of college students' online entrepreneurship and establish the disturbing fuzzy matrix

According to the impact degree of various risk factors on college students' online entrepreneur, there are 32 experts consisting of college experts and entrepreneurship outside school, through jointed consultations to determine comment grade which can be divided into high, higher, normal, 
lower, low 5 types, and they score then to summary respectively in order to form the table of college students online entrepreneurship management risk factors level summary table, as shown in table 3 .

Table1 College students' online entrepreneur risk comprehensive evaluation

\begin{tabular}{|c|c|c|c|c|c|c|}
\hline \multirow{2}{*}{$\begin{array}{l}\text { The First } \\
\text { Layer Index }\end{array}$} & \multirow{2}{*}{$\begin{array}{l}\text { The Second } \\
\text { Layer Index }\end{array}$} & \multicolumn{5}{|l|}{ Risk grade } \\
\hline & & higher & high & medium, & low & lower \\
\hline \multirow[t]{4}{*}{$\mathrm{U}_{1}$} & $\mathrm{U}_{11}$ & {$[0.40,0,50]$} & {$[0.30,0.35]$} & {$[0.10,0.18]$} & {$[0.05,0.10]$} & {$[0.01,0.05]$} \\
\hline & $\mathrm{U}_{12}$ & {$[0.05,0.10]$} & {$[0.12,0.18]$} & {$[0.45,0.55]$} & {$[0.18,0.22]$} & {$[0.08,0.12]$} \\
\hline & $\mathrm{U}_{13}$ & {$[0.01,0.05]$} & {$[0.40,0.50]$} & {$[0.30,0.38]$} & {$[0.10,0.20]$} & {$[0.05,0.10]$} \\
\hline & $\mathrm{U}_{14}$ & {$[0.05,0.10]$} & {$[0.25,0.30]$} & {$[0.50,0.60]$} & {$[0.01,0.05]$} & {$[0.00,0.00]$} \\
\hline \multirow[t]{6}{*}{$\mathrm{U}_{2}$} & $\mathrm{U}_{21}$ & {$[0.10,0,20]$} & {$[0.35,0.40]$} & {$[0.25,0.30]$} & {$[0.02,0.10]$} & {$[0.02,0.10]$} \\
\hline & $\mathrm{U}_{22}$ & {$[0.40,0.50]$} & {$[0.30,0.35]$} & {$[0.14,0,20]$} & {$[0.05,0.10]$} & {$[0.01,0.05]$} \\
\hline & $\mathrm{U}_{23}$ & {$[0.30,0.35]$} & {$[0.40,0.50]$} & {$[0.15,0.22]$} & {$[0.01,0.05]$} & {$[0.01,0.05]$} \\
\hline & $\mathrm{U}_{24}$ & {$[0.10,0.15]$} & {$[0.20,025]$} & {$[0.40,0.50]$} & {$[0.05,0.10]$} & {$[0.10,0.15]$} \\
\hline & $\mathrm{U}_{25}$ & {$[0.15,0.20]$} & {$[0.15,0.20]$} & {$[0.18,0.22]$} & {$[0.30,0.36]$} & {$[0.18,0.22]$} \\
\hline & $\mathrm{U}_{26}$ & {$[0.18,0.24]$} & {$[0.40,0.45]$} & {$[0.24,0.30]$} & {$[0.05,0.01]$} & {$[0.05,0.01]$} \\
\hline \multirow[t]{5}{*}{$\mathrm{U}_{3}$} & $\mathrm{U}_{31}$ & {$[0.30,0.35]$} & {$[0.35,0.40]$} & {$[0.15,0.20]$} & {$[0.10,0.15]$} & {$[0.01,0.05]$} \\
\hline & $\mathrm{U}_{32}$ & {$[0.10,0.15]$} & {$[0.15,0.20]$} & {$[0.20,0.30]$} & {$[0.32,0.40]$} & {$[0.05,0.10]$} \\
\hline & $\mathrm{U}_{33}$ & {$[0.40,0.50]$} & {$[0.32,0.38]$} & {$[0.08,0.12]$} & {$[0.05,0.08]$} & {$[0.05,0.08]$} \\
\hline & $\mathrm{U}_{34}$ & {$[0.15,0.20]$} & {$[0.30,0.35]$} & {$[0.38,0.43]$} & {$[0.05,0.10]$} & {$[0.01,0.05]$} \\
\hline & $\mathrm{U}_{35}$ & {$[0.08,0.13]$} & {$[0.24,0.30]$} & {$[0.35,0.40]$} & {$[0.20,0.25]$} & {$[0.05,0.10]$} \\
\hline \multirow[t]{4}{*}{$\mathrm{U}_{4}$} & $\mathrm{U}_{41}$ & {$[0.20,0.25]$} & {$[0.25,0.30]$} & {$[0.30,0.35]$} & {$[0.15,0.20]$} & {$[0.01,0.05]$} \\
\hline & $\mathrm{U}_{42}$ & {$[0.30,0.35]$} & {$[0.35,0.40]$} & {$[0.13,0,18]$} & {$[0.06,0.12]$} & {$[0.05,0.10]$} \\
\hline & $\mathrm{U}_{43}$ & {$[0.44,0.50]$} & {$[0.20,0.28]$} & {$[0.15,0.20]$} & {$[0.06,0.12]$} & {$[0.05,0.10]$} \\
\hline & risk $\mathrm{U}_{44}$ & {$[0.06,0.13]$} & {$[0.15,0.20]$} & {$[0.20,0.25]$} & {$[0.40,0.45]$} & {$[0.05,0.10]$} \\
\hline \multirow[t]{4}{*}{$\mathrm{U}_{5}$} & $\mathrm{U}_{51}$ & {$[0.10,0.15]$} & {$[0.45,0.50]$} & {$[0.20,0,25]$} & {$[0.08,0.13]$} & {$[0.08,0.13]$} \\
\hline & $\mathrm{U}_{52}$ & {$[0.08,0.13]$} & {$[0.22,0.27]$} & {$[0.32,0.42]$} & {$[0.15,0.20]$} & {$[0.03,0.08]$} \\
\hline & $\mathrm{U}_{53}$ & {$[0.38,0.42]$} & {$[0.22,0.27]$} & {$[0.15,0.20]$} & {$[0.03,0.08]$} & {$[0.08,0.13]$} \\
\hline & $\mathrm{U}_{54}$ & {$[0.08,0.14]$} & {$[0.30,0.35]$} & $0.22,0.27]$ & {$[0.15,0.20]$} & {$[0.12,0.18]$} \\
\hline
\end{tabular}


It can be concluded from table 1 the fuzzy relations matrix $\mathrm{R}_{\mathrm{ij}}$ of disturbing of college students' online entrepreneur risk.

4.5 Use disturbing fuzzy synthetic evaluation method and determine the disturbing fuzzy comprehensive evaluation

According to the disturbing fuzzy comprehensive evaluation theory, use the formula $B_{i}=A_{i} \circ R_{i}$, first evaluates level of disturbing fuzzy comprehensive, then get the calculating result $U_{i}$, which do synthetic vector operations $\mathrm{M}(\otimes, \oplus), \mathrm{R}_{\mathrm{i}}$ is the single factor judgment matrix and the weight vector $A_{i}$ Such as $B_{1}$, the calculation as follows:

$$
\mathrm{B}_{1}=\mathrm{A}_{1} \circ \mathrm{R}_{1}=([0.35,0.40],[0.30,0.35],[0.25,0.30],[0.15,0.20],[0.08,0.10])
$$

Similarly we can conclude the $\mathrm{B}_{2}, \mathrm{~B}_{3}, \mathrm{~B}_{4}, \mathrm{~B}_{5}$.

Then use the result of level of disturbing fuzzy comprehensive evaluation to construct asingle factor judging matrix R of secondary disturbing fuzzy comprehensive evaluation $\mathrm{R}$.

Therefore $\mathrm{B}=\mathrm{A} \circ \mathrm{R}=([0.30,0.36],[0.30,0.35],[0.24,0.25],[0.18,0.22],[0.15,0.18])$.

Then the vector $B$ of each interval mean values: $\bar{B}=\left(\begin{array}{lll}0.33, & 0.325,0.245, & 0.2,0.165\end{array}\right)$.Last

it has been normalized, so get $\bar{B}=(0.261,0.257,0.194,0.158,0.131)$. According to the principle of maximum membership degree, college students' online entrepreneurship risk level is higher. Use the principle offuzzy distribution, from the above calculation results shows within the risk factors of influencing college students' online entrepreneurship, management risk ranks highest, therefore college students need to adopt a scientific methodto reduce the risk of entrepreneurship to the greatest extent during the process of entrepreneurship.Followed by risks of social environment and project risks, the risk oftechnology and colleges' entrepreneurship is lower.

\section{Strategies of reducing the risk of college students' online entrepreneurship}

Due to the empirical analysis of risks of college students' online entrepreneurship, among the factors affecting college students' starting online business risks, there are several affecting factor mainly including risk management, social and environmental factors, project risks, technical risks and several other. The paper puts forward 4 suggestions on college students' starting online entrepreneurship risk.

(1) They should participate in social practice, do market research deeply,and assess entrepreneurship programsintegratedly. Although college students have some corresponding knowledge of management theory, their social experience is shallow, lacking the necessary capacity of practical applications. Therefore it is advocated for college students to participate in social practice activities and go deep in the enterprise as far as possible, and apply the theoretical knowledge what they have learnt tothe practice of enterprise's management, alwaysfocus on the customer, learn to manage enterprise scientifically. There are many forms for college students' online entrepreneurship, for example do market surveys, go deep to study about enterprise, evaluate the projectby means of proper evaluation methods, and try to make research results accurate, real-time.

(2) They should learn about business management knowledge to lift the enterprise operation level. Different corporate management requires different knowledge, as college students' entrepreneur should intensify their theory study of enterprise's management and apply into the corresponding practice, to minimize business failures as far as possible and to improve the level of 
running. Various managements can be conducted based on various management ranges, such as marketing management,logistics management, human resource management, financial management and so on.

(3) They should intensify manage website operations, do data mining and integrate datasystematically. Themost direct way to show the success or failure of online entrepreneurship is data and traffic. If a website operatesimproperly, the orders will be decreased, how to translate the potential market for the order is a key factor. So college student entrepreneurs need to constantly update the latest site data, using a variety of data mining and integration in order to expand customer visits, according to the present statistical data to analyze problems existing in the Interwork marketing as well as customer consumption characteristics, then get first-hand information, which makes marketing pointed,validate. At the same time enhance the application of information technology, and the effective use of the website.

(4) The Government should perfect the relevant laws of e-commerce, e-taxation, and electronic evidence in order to adapt to the development of e-commerce.

\section{References}

[1]Chen Junyi. Risk analysis of college students ' e-commerce venture. J. science and economy in Inner Mongolia, 2012 (8): 18-20.

[2]] LouXingchen. College students ' entrepreneurial risk and countermeasures in colleges and universities. J. Journal of Anhui science and Technology University, 2012(3):126-128.

[3]Cheng Heping. Network business risk analysis and countermeasure study of college students. J. times of financial, 2011(10):124-125.

[4] Yang Haijuan. Feasibility analysis and countermeasures of college students ' starting online business. J Chinese and foreign entrepreneurs, 2011 (2): 74-75.

[5] Suifei. Analysis of entrepreneurial model of network for college students. J. education of Henan (middle), 2012 (6): 78-79.

[6] Le Zhongjian, and $\mathrm{Wu}$ Qinfen, and Chen Ruihua. College students' entrepreneurial risk analysis based on college campus e-commerce environemnt J. modernization of the Mall, (2008): 156.

[7] Song Jianji E-commerce risk assessment based on fuzzy comprehensive evaluation method J. China circulation economy, 2011 (7): 107-110.

[8] Chen Peiyou, Li Xing Improvement of fuzzy comprehensive evaluation algorithm J. Journal of Heilongjiang Institute of science and technology, 2006 (11): 396-399.

[9]He Beifang, Yu Zhanglin, Liu Zheng.Mathematical model and its application in multi-level fuzzy comprehensive evaluation J. theory and practice of systems engineering, 1989 (12): 1-6.

\section{Acknowledgement}

This work is supported by the 2012 National Students' Innovative Entrepreneurship Training Program (201210347001) project funding. This work was funded by the Zhejiang Natural Science Foundation, project NO.Y1111000. 